\title{
Foundations of a robust social-ecological system: irrigation institutions in Taiwan
}

\author{
WAI FUNG LAM \\ Department of Politics and Public Administration, The University of Hong Kong, Pokfulam Road, HONG KONG. \\ Tel: (852) 2859 2391. Email: dwflam@hku.hk
}

\begin{abstract}
The decline of agriculture in Taiwan has adversely affected the incentives of farmers and the government to engage in irrigation management. Despite that, Taiwan's irrigation systems have shown a high degree of robustness. This study seeks to understand how institutions have contributed to the robustness of Taiwanese irrigation. Conceptualizing an irrigation system as a social-ecological system (SES), this study examines the development and design of Taiwanese irrigation institutions, and how these institutions have enabled farmers and irrigation managers to cope with the dynamics in the SES, and hence contributed to the system's robustness.

The study has found that the robust systems are built upon institutions that allow effective coordination of the activities of a multitude of farmers, enhance the development and sustenance of a repertoire of ideas, and nest the problem-solving efforts of various scopes and scales in a complementary manner. The institutions enable individuals and organizations at different levels to engage in continuous learning and adaptation that, in turn, facilitates the systems' adaptation to the changing environment.
\end{abstract}

\section{Robustness and change in Taiwanese irrigation}

Taiwan's irrigation sector has been facing a series of challenges in the past decades. As the country's economy has developed, agriculture has lost its comparative advantage and become economically non-viable. The overproduction of paddy rice in Taiwan and worldwide has kept grain prices low; the opening up of Taiwan's agricultural produce market to international competition as a result of Taiwan's entry into the WTO is going to make agriculture even more difficult to sustain (AERC, 1999, 2000, 2001). The decline of agriculture has driven the rural youth to cities, resulting in rapid ageing of the farming population. ${ }^{1}$

An earlier version of the paper was presented at the Workshop on the Workshop III, June 2-6, 2004, Indiana University, Bloomington. The research was supported by a grant (HKU7233/03H) from the Hong Kong Research Grants Council.

1 As of 2001 , more than $37 \%$ of the heads of farm households in Taiwan were over 65 of age (COA, 2003). 
The decline of agriculture has reduced the incentives of the Taiwanese government and farmers to engage in irrigation management. As farmers do not earn their main income from agriculture, they see little incentive to put resources into collective action for irrigation management. As of 2000, agriculture accounted for less than 3\% of Taiwan's GDP, though it used up almost $80 \%$ of the country's available water (COA, 2003). ${ }^{2}$ Questions have been raised as to whether more water should be transferred to the domestic and industrial sectors.

Irrigation management is never a mere local, engineering issue. Particularly in Taiwan, agriculture and irrigation has a long history of government involvement (Stavis, 1974; Foster, 2001). Since the transformation of the Taiwanese polity from an authoritarian regime to one of competitive party politics in the late 1980s, politicians have not hesitated to exploit issues of agriculture and irrigation to advance their political interests (Lam, 2005).

Despite these challenges, irrigation in Taiwan remains in good shape. Irrigation infrastructure is relatively well maintained, largely due to continual investment by government and local Irrigation Associations (IAs); water distribution and allocation in the field is kept in good order. ${ }^{3}$ Although active voluntary labor can no longer be found, the social infrastructure that has evolved over years of cooperation has not deteriorated too badly. The close links between the Irrigation Associations and farmers remain relatively solid. ${ }^{4}$

At the national level, the irrigation sector has been successful in fending off the demands for a transfer of water rights from agriculture to other sectors. While politicization has generated uncertainties, the irrigation sector has been able to resist the government's attempts to tighten control. Unlike other East Asian countries such as South Korea where the decline of agriculture has been accompanied by the nationalization of irrigation institutions, Taiwan's irrigation sector is moving towards even higher degrees of self-governance and autonomy.

Taiwan's irrigation systems have shown a high degree of robustness, which refers to the maintenance of some desired system characteristics, despite fluctuations in the behavior of its component parts or its environment (Carlson and Doyle, 2002; Jen, 2002; Anderies, Janssen, and Ostrom, 2004). A question

2 As of 2000, the annual precipitation of Taiwan was 90.5 billion cubic meters; about 19.5 billion cubic meters of water was available for use. About 15.4 billion cubic meters was used for agriculture.

3 The latest fieldwork was conducted in January 2004. With the cooperation of the Council of Agriculture and the Agricultural Engineering Research Center, the author visited four of the 17 IAs in Taiwan. The four IAs, namely Taoyuen, Chianan, Hualien, and Pingtung, are representative of major hydrological and socio-economic types of irrigation systems in the country. During the visit, the author interviewed IA staff, visited local working stations, met with Irrigation Group leaders.

4 During the fieldwork in early 2004, I conducted extensive interviews with government officials, IA officials, IG leaders and ordinary farmers. I explicitly asked the interviewees to assess the degree of farmers' participation and involvement in IA activities. A majority of them agreed that, while active, enthusiastic participation can no longer be found nowadays, the close working relationships among the farmers and between the farmers and the IAs have not deteriorated. Whenever issues affecting the IAs come up, farmers are willing to express their views and show concern. 
of major policy and theoretical interest is: In what ways have the Taiwanese irrigation institutions enabled the systems to cope with the shocks, and to adjust to the changing environment? In other words, what is the institutional foundation of the robustness of Taiwanese irrigation? Conceptualizing an irrigation system as a social-ecological system (SES), this study addresses the question by examining the origin and development of Taiwanese irrigation institutions, and how the institutions cope with the complexity in a SES. ${ }^{5}$

\section{The political economy of Taiwanese irrigation: shocks and challenges}

Government has played a dominant role in Taiwan's economic development (Liao, Huang, and Hsiao, 1986; Amsden, 1988; Moore, 1993). In the 1950s and 1960s, through a series of exploitative measures such as barter of fertilizer for grains and compulsory grain purchases, the Taiwanese government extracted surplus out of agriculture to help launch industrialization. By the late 1970s, Taiwan's industry took off. In the process of industrialization, agriculture lost out. Taiwan's agriculture is dominated by paddy rice. ${ }^{6}$ The overproduction of paddy rice in Taiwan and worldwide, together with the decreasing demand for staples as a result of economic development, has put tremendous pressure on grain prices (Wu Huang, 1993; Pingali, Hossain, and Gerpacio, 1997). Since 1990, agriculture has accounted for less than $3 \%$ of Taiwan's GDP. ${ }^{7}$

The structure of Taiwan's agriculture is not conducive to diversification. Since 1990, the average landholding size of farm households in Taiwan has been less than one hectare. ${ }^{8}$ The small landholding size prevents effective use of machines, and renders infrastructure investment uneconomical. Although farmers cannot earn a living by farming, ${ }^{9}$ they are generally unwilling to sell their lands and leave agriculture. ${ }^{10}$ Farmers' bond of land might be a reason, but many farmers expect

5 The study is based upon information collected in a series of fieldtrips to Taiwan in the last decade. With the help from the Council of Agriculture, the IAs, and a number of funding agencies, the author has been able to keep track of the development of Taiwanese irrigation by conducting regular visits to the IAs every one to two years since the early 1990s.

6 Taiwan's agricultural potentials are substantial due to high precipitations and the warm temperate weather; the distribution of precipitation, however, is highly uneven. Much precipitation falls in the summer; and water is very scarce in the winter. Without irrigation, farming is simply impossible in many areas in the country. The rough topography of Taiwan is not conducive to irrigation. High gradients of terrains together with short rivers result in rapid water flows and hence high wash-out rates.

7 In 1952, for instance, agriculture accounted for 32\% of Taiwan's GDP; the percentage dropped to $28.5 \%$ in 1960 (CEPD, 1996).

8 As of 2001, more than $92 \%$ of Taiwan's farm households had a landholding size of less than 1 hectare.

9 As of 2001, the average annual income for farmers per capita was about NT224,000 (around US $\$ 6,600$ in 2001), which was around $70 \%$ of the average annual per capita income for non-farm households.

10 As of 2001 , there were about 726,000 farm households in Taiwan, which was about $10 \%$ of the total number of households in the country. Such a percentage has remained quite steady. It is interesting 
that some day their lands might be re-zoned, which would mean a substantial increase in land value. For farmers who derive their major incomes from nonfarm activities, they could afford to keep the lands and wait.

While agriculture has lost its economic viability, its importance in Taiwan's political economy remains. Ever since its inception, the Taiwanese government has been in a dormant but confrontational relationship with the People's Republic of China (PRC). To the Taiwanese government, a war across the Taiwan Strait is not only plausible but inevitable; national security has always been a paramount concern (Williams, 1994; AERC, 1999, 2000, 2001). Food security is a key imperative underlying Taiwan's agricultural policy.

To maintain food security, the government has to ensure that the agricultural potential be preserved so that Taiwan has the ability to feed its population in the case of embargoes. The government has promulgated zoning laws, which strictly control changes of land use of paddy fields. In return, the government has provided the farmers with a variety of subsidies, including guaranteed procurement of grains at preferential prices, subsidies for fallowing, and substantial rural infrastructure projects. The government has been subsidizing the irrigation sector substantially. During the period from 1993 to 1997, for example, government subsidy accounted for almost $70 \%$ of the total expenditures of the IAs. ${ }^{11}$

The political economy of agriculture as described has impacts on irrigation management at two levels. At the field level, unlike in the past when irrigation water was an important production factor that could affect farmers' income, farming nowadays is considered a supplementary economic activity, which, in many circumstances, is not for profit making but for keeping the farmlands cultivable. Such a low-incentive mode of agriculture poses serious challenges to Taiwanese irrigation management, which is built upon farmers' participation and farmer-government synergy.

At the sectoral level, as the irrigation sector becomes more reliant on government subsidies, and farmers face little incentive to monitor the IAs, the government feels obliged to impose tighter control to make sure that public monies are appropriately spent. Another challenge concerns water resource allocation and utilization across sectors. Many have argued that, as the importance of agriculture decreases, more water should be transferred to domestic and industrial uses. Irrigation officials and the IAs need to justify and defend their water rights.

While the macro political-economic changes have posed serious shocks and challenges to Taiwanese irrigation systems, the systems have been able to cope with the challenges, and retain a good level of vibrancy. How do we understand

to note that the total number of 'full-time' farm households, who derive their major income from farming, has been on the rise in the last ten years. In 1992, there were about 100,000 full-time farm households in Taiwan; by 2001, the number had increased to more than 140,000 (COA, 2003).

11 For detailed figures, see AERC (1999). 
the foundation of the robustness of Taiwanese irrigation? In particular, in what ways have Taiwanese irrigation institutions contributed to the robustness?

\section{The development of Taiwanese irrigation institutions}

Taiwanese irrigation institutions are a product of both rational institutional choices and the temporal dynamics of evolution. To understand how the institutions have contributed to the robustness of irrigation systems, an analyst needs to examine the historical development of the institutions so as to identify the issues, concerns, and imperatives that underlayed, activated, and constrained the institutions' evolution (Pierson, 2004; Thelen, 2004). In particular, the analyst needs to pay attention to the tensions embedded in the design of the institutions, the reasons why alternative institutional designs were not adopted, and the conditions for the stability and viability of the institutions and hence the irrigation systems.

\subsection{The origin of Taiwanese irrigation institutions}

Government involvement in Taiwanese irrigation began when the island was ceded to Japan at the end of the nineteenth century; before then irrigation was largely a matter in the private domain. Colonial governance is by nature extractive and exploitative; the Japanese were no exception (Ka, 1995). The motive of the government's intervention in irrigation was to increase Taiwan's agricultural productivity so that more resources could be generated for the industrial and domestic needs of the Japanese homeland.

Like other colonial governments, the Japanese faced two fundamental dilemmas. First, they had to secure the cooperation of the local population without compromising the colonial government's authority; second, they had to maximize what they could extract from the colony without overdoing it and hence provoking the local population. In irrigation management, these dilemmas posed as the imperatives for institutional choice, which inevitably limited the options of institutional design available to the colonial government.

Given the dilemmas, the colonial government adopted a parastatal institutional design featuring several characteristics. First, instead of nationalizing existing irrigation systems that had been built and managed by local communities, the government promulgated an executive order that irrigation facilities deemed essential to the 'public interest' of agricultural development were to be put under the auspice of some corporate bodies called Irrigation Groupings (the predecessors of the Irrigation Associations). While the Irrigation Groupings were presumably farmers' organizations, and were given an independent legal status and a certain degree of autonomy, they were subject to close supervision, monitoring, and assistance by the colonial government (Chen, 1997). Under an Irrigation Grouping was a network of self-organizing Irrigation Groups (IGs), which were responsible for managing daily operation and maintenance (O\&M) 
below the sublaterals. Although the IGs did not enjoy any formal legal status, they provided a broad institutional framework for farmers' organizing efforts in the field.

Second, the self-governing status of the Irrigation Groupings (and later the Irrigation Associations) established common property rights of the irrigation facilities. As farmers perceived themselves to be the owners of their Groupings and systems, they were in general more willing to contribute to the construction and management of irrigation facilities. In fact, many large-scale irrigation projects initiated and spearheaded by the government would not have existed without farmers' generous contributions. ${ }^{12}$

Third, large-scale infrastructural development has always been a core component of irrigation development in Taiwan. The design of Taiwanese irrigation institutions, in particular the rules concerning water delivery, have been closely related to infrastructural and technological developments. For example, the size and composition of Irrigation Groupings was largely correspondent to the government's efforts to consolidate small irrigation systems into larger systems.

Fourth, in a colonial setting where the government needed to co-opt the local elite, the parastatal design provided an ideal institutional infrastructure. From the perspective of the colonial government, the parastatal organizations were convenient arenas for managing the local elite. As long as the government was able to manipulate the ways these organizations operated, it could maintain political stability.

\subsection{The development of Taiwanese irrigation institutions during the Nationalist rule}

After World War II and the Chinese civil war in the 1940s, the Chinese Nationalist (Kuomintang, KMT) government fled to Taiwan. The resumption of Chinese rule on the island inevitably triggered a process of institutional building and restructuring at different levels of governance; it was the context in which irrigation institutional changes took place.

When the Nationalists first arrived in Taiwan, they found themselves dealing with an indifferent population who had little cognitive or affective bond with the new government. The political repressions that followed further alienated the Taiwanese locals. Ironically, the Nationalists found themselves facing a dilemma similar to what the Japanese faced half a century earlier - on one hand, the establishment of governance required the consent, or at least acquiescence, of the locals; on the other hand, the government did not want to compromise its authority. Moreover, a policy imperative of the government was to produce enough paddy to feed the large number of migrants fleeing Mainland China. An 
extractive agricultural policy was deemed a necessity, which further attenuated its relations with the local farming population.

The Nationalist government found strengthening the existing parastatal irrigation institutions suited their needs. It could reconcile the government's need to exert control over the local population on the one hand, and the imperative to placate the local population so as to secure their cooperation on the other. Also, the network of Irrigation Groups provided an effective means to infiltrate and mobilize the rural communities.

The Irrigation Groupings were renamed Irrigation Associations; some restructurings of the Irrigation Associations, such as merging some small IAs into bigger ones, were undertaken to rationalize the IAs' operation. Perhaps the most important change was to give the IAs certain public mandates and authority, and to turn them into 'public entities'. Such a status differentiated the IAs from other local organizations such as the Farmer Associations, putting the IAs under closer government scrutiny (Chen, 1997).

The Nationalist government also adopted a series of measures to improve agricultural productivity, including land reforms, farmland consolidation, large-sale infrastructure projects, and agricultural procurement policies. The implications of these measures for irrigation management and institutional design were significant. First, farmland consolidation and large-scale infrastructure projects made rotation irrigation on a large-scale possible. Effective practice of rotation irrigation required the effective collective action of farmers in the field; an institutional design that could facilitate farmers' self-organizing effort became imperative. Second, by putting in substantial inputs, the government became an essential player in irrigation management. Unlike the colonial government who sought to minimize involvement, the Nationalist government was not hesitant to get involved. As government inputs increased, managing the farmer-government partnership in irrigation management became a great challenge.

Taiwan's irrigation institutions are not static. In particular, their selfgoverning character has been subject to constant challenges. Over the years the government has attempted to restructure or replace these self-governing institutions. From the government's perspective, the parastatal design is a twoedged sword. While it allows the government to exert control without paying a high cost, it poses the risk of authority leakage. The potential conflict between control and autonomy is the tension inherent in the parastatal design.

The industrialization of Taiwan's economy attenuated the tension. As farming became less lucrative, the government found itself having to put in large amounts of resources in the irrigation sector. The government had to make sure that the money was well spent; the incentive to tighten control over the IAs was substantial. The first attempt to tighten control took place in the 1970s, when the government abolished the IA Chairman elections and turned the positions into government appointments. The operation of the IAs was put under stringent scrutiny, with a series of administrative measures taken to rationalize the IAs' 
financial and personnel procedures to improve the IAs' operational efficiency. Although the self-governing operation of the IAs was restored in the early 1980s, the possibility of turning the IAs into a government agency was seriously explored as an alternative. In the early 1990s, the issue of whether the IAs should be turned into a government agency (hence irrigation management be nationalized) was again put on the political agenda. In 1993, a bill was passed in the legislature stipulating that the IAs would be turned into government agencies in three years. Although the bill was repealed by another bill in 1996, the tension between government control and local governance drags on.

\subsection{Dynamics of institutional evolution of Taiwanese irrigation}

One could easily discard the various (failed) attempts to 'nationalize' the IAs as merely a show of political maneuvering. Yet in each episode of the process of (attempted) institutional change, individuals involved did ponder about the viability of the existing as well as alternative institutional designs, before they came up with the structural choice decisions. Examining the calculus underlying these decisions can help identify issues and concerns underlying the institutional design. It can also provide information for conducting thought experiments on the viability of alternative institutional designs that were not adopted (Tetlock and Belkin, 1996; Sylvan and Majeski, 1998). Moreover, each episode of institutional change is a manifestation of the unfolding of the process of institutional development. Examining these episodes allows us to identify the mechanisms and dynamics underlying the institutions' evolution (Griffin, 1992; Buthe, 2002; Pierson, 2004).

The discussion of the possibility of turning the IAs into government agencies resulted in heated debates and studies of the parastatal design, and also of the viability of using a bureaucratic mode to manage irrigation (CAEA, 1995; Chen, 1996, 1999; Chen, S.C., 1997; AERC, 1999, 2000, 2001). From these studies, one could summarize several arguments that the different actors involved in the debates seemed to agree on. First, the IAs are built upon the concept of common property. As the construction and development of much irrigation infrastructure involved significant contribution from farmers and local communities, turning the IAs into government agencies would infringe the property rights of the communities.

Second, most of the IA staff do not possess the necessary educational qualifications for the civil service status. Taking care of the IA personnel would be an insurmountable challenge in any move to nationalize the IAs. Most studies, however, did not portray the lack of educational qualifications to be a negative attribute. Most of the IA staff come from local communities, who have worked in the communities for an extended period of time. It is the experiences of these IA staff and the close relationships that they have developed with the local communities that help facilitate water delivery. In fact, the retirement of 
the more experienced staff has become a problem to many IAs. ${ }^{13}$ Given the meticulous character of Taiwanese irrigation management, it is inconceivable how a bureaucratic mode of management could manage the large array of collective action in water delivery (Lam, 2005, 2006).

Third, nationalizing the IAs would require correspondent administrative restructuring in the central government and, hence, incur high administrative costs. In fact, the Irrigation Bureau in the Council of Agriculture (the Taiwanese equivalent to a ministry of agriculture) was only established in 2004; before then it was only a small section under the Bureau of Forestry. Changing the parastatal mode to a bureaucratic mode would simply require a complete overhaul of the government's agricultural bureaucracy.

Fourth, although government input in the irrigation sector has been increasing, nationalizing the IAs might not necessarily bring about a reduction of financial burden. While some IAs are having serious financial problems, some others, particularly those near the urban areas, have shown much entrepreneurship in generating revenues (Lam, 2001, 2005). Nationalizing the IAs would only narrow the revenue base for the irrigation sector.

Fifth, it has been strongly argued that the IAs embody the ideal of selfgovernance that any democratic society should treasure. While problems exist in the elections of chairmen and farmers' representatives, they could be dealt with by better institutions and election rules.

All these arguments suggest that, while the parastatal irrigation institutions might not be perfect, the bureaucratic alternative would not have been more viable, or better able to cope with the task of irrigation management. Moreover, the development of Taiwanese irrigation institutions has shown a high degree of path dependency. The parastatal institutions are heavily locked in - the significant increasing returns effect tends to reinforce adaptation to the initial institutional choice, rendering any shift to alternatives increasingly costly and impracticable (Arthur, 1994; Pierson, 2004). Three mechanisms have played an important role in generating the increasing returns.

The first mechanism is the common property rights upon which the IAs are built. To many farmers, their irrigation systems are the product of the contribution and collective efforts of their ancestors; and the IAs are the institutional embodiments of the common property. There is a strong sense of collective ownership among farmers, which has given them strong incentives to preserve the IAs as a way to cling to the common property. Moreover,

13 Since the 1990s, the recruitment of staff of the IAs has been managed by the government. Applicants are required to sit a public service examination to be considered for the IA jobs. A result is that many new recruits in the last few years have had an education qualification and been younger in age. During my fieldwork, however, both IA managers and farmers opined that the new recruits, while better educated, do not have the necessary social skills and social networks to facilitate water delivery. 
the diffused nature of common property rights makes it very difficult for the government to nationalize the irrigation institutions and systems.

The second mechanism is technological lock-in - the close relationship between institutional design and irrigation technologies triggers the dynamics of mutual reinforcement. While the institutions sustain the use and operation of particular irrigation infrastructure or technology, the continual use and investment in the infrastructure or technology makes the institutions more asset-specific and difficult to change. As discussed above, Taiwanese irrigation institutions are designed in conjunction with the development of irrigation technologies. In particular, the operational needs of rotation irrigation have largely determined the design of irrigation institutions and water delivery procedures. In the Chianan area where rotation irrigation is most seriously practiced, for example, effective water delivery depends on the ability of the Irrigation Groups at the sublateral level to coordinate their schedules of water delivery. To substitute for the farmers' effort, if it ever be an option, would require significant infrastructural input and restructuring, which would be extremely costly and ineffective.

The third mechanism is institutional lock-in. Institutions tend to favor learning of particular activities, and to reproduce behavior that is consistent with the logic of the institutions. In water delivery, the parastatal institutions emphasize the importance of local knowledge, networking, and embedding irrigation staff in local communities. The institutions tend to encourage farmers and front-line IA staff to reproduce water delivery rules and procedures for specific situations in the same image, which further reinforce the perceived viability of the existing institutions. Politically, the parastatal design embodies and continually reinforces the concept of farmers' ownership. Such a concept has been adamantly promoted by local politicians and IA staff who have significant stakes in the survival of the IAs.

Given that institutional change is not a purely rational process, there is no guarantee that existing institutions are necessarily efficient (Pierson, 2004). An interesting question, then, is what are the attributes of Taiwanese irrigation institutions that have contributed to the robustness of Taiwanese irrigation systems? In particular, an irrigation system is a social-ecological system involving intricate relationships between and among human and biophysical elements. How do the irrigation institutions enable the individuals involved to cope with the complexity?

\section{An irrigation system as a social-ecological system}

An irrigation system can be conceptualized as a complex social-ecological system (SES) in which human agents in different capacities and of different attributes engage in continuous interaction in response to one another and the biophysical environment (Berkes and Folke, 1998; Anderies, Janssen, and Ostrom, 2004). 
Interactions among human agents give rise to emergent systemic attributes that determine the system's ability to adapt to the turbulent environment. The potentials of human cogitation and strategic thinking further increase the complexity involved in a SES. A SES is complex, epistemic, hierarchic.

\subsection{A complex system}

A complex system is constituted by a large number of autonomous units that constantly interact with one another, as well as the environment of which they are parts. A complex system has the process of self-organization built in. 'Selforganization is a process in which a pattern at the global level of a system emerges solely from numerous interactions among the lower-level components of the system. Moreover, the rules specifying interactions among the system's components are executed using only local information, without reference to the global pattern' (Camazine et al., 2001). A complex system is complex not because it involves a large number of units or rules; instead, complexity pertains to the emerging systemic properties that are not present at the unit level.

An irrigation system is a complex system of which the working order is the emergent systemic quality constituted by numerous decisions and actions of actors of different capacities in disparate situations. A well-performed irrigation system is characterized not only by a well-maintained infrastructure, but more importantly a productive working order of farmers (as resource users) and irrigation managers (as infrastructure providers). Such a productive working order is an emergent pattern that is not the outcome of the command of a central pacemaker.

Water in a system flows from the head end to the tail end through a network of canals. The flow nature of water implies a high degree of interdependence among individuals involved in irrigation (Ostrom and Gardner, 1993; Lam, 1998). While the task of irrigation management involves high degrees of interdependence, decisions by individuals as to what to do in a particular situation are often highly independent. For instance, a farmer at the head end who tries to stop the water in a canal a little longer in order to divert a little more water to his fields would unlikely be able to comprehend how his seemingly trivial and innocent act might affect the operation of the system as a whole. The challenge of coordination in such a complex setting is substantial (Lansing, 1991).

\subsection{An epistemic system}

A SES is activated by human beings who are able to (1) think and foresee action-outcome links, (2) acquire and appreciate value and meaning of action, and (3) learn and conduct trial-and-error. The architecture of human cognition takes on an important role in understanding human choice and action in a complex system (Simon, 1985; Jones, 2003). Individuals develop mental models to frame the world as they see it. The mental models help individuals make 
sense of the world by (1) stipulating the definition of the problem at hand, (2) constituting preferences, (3) laying out causal action-outcome relationships, and hence possible alternative courses of action, and (4) specifying criteria for the choice of alternatives. Choices are embedded in the prior question of how the mental model is built in the first place. ${ }^{14}$ In a complex situation, rationality cannot be assumed but has to be explained (Jones, 2003).

Several characteristics of mental model building are important to the understanding of the SES. First, human beings' abilities of empathy and engaging in reciprocal interaction create the potential for developing mental models for mutual betterment (Ostrom and Janssen, 2002). Mental models are embedded in the broader cultural and social understanding of a community of individuals, who share common experiences and predispositions of action (North, 1990). Second, while a mental model simplifies, it also confines individuals' vision. Problems arise when a mental model no longer captures the essence of a problem as the problem evolves. How to strike a balance between stability and change affects the viability of individuals' adaptive efforts (Denzau and North, 1994). Third, human beings are endowed with the ability to imagine and to come up with new ways of looking at their circumstances. When enough evidence about the inadequacy of a particular model accumulates, the mental model in use could be replaced.

The specific features of human cognition have implications for the study of irrigation institutions in Taiwan. First, prior studies have shown that the success of Taiwan's irrigation management hinges upon a large array of diverse local institutions developed by farmers in disparate local communities to cope with irrigation problems that are location-specific and time-specific (Moore, 1989; Lam, 1996a). As Denzau and North (1994) argue, institutions are simply mental models externalized. What are the mental models in the repertoire that have been drawn upon by the farmers in coping with the macro disturbances? Second, institutions that help generate and maintain such a diverse repertoire of mental models are instrumental to the robustness of the system. What is the design of these institutions and how does it work? Third, a mental model is effective only if it is shared and commonly understood by a community of individuals. What is it in the Taiwanese system that makes the shared learning possible?

\subsection{A bierarchic system}

Simon (1962) defines a hierarchic system as one 'that is composed of interrelated subsystems, each of the latter being, in turn, hierarchic in structure until we reach some lowest level of elementary subsystem'. Different tasks involved in an irrigation system might be of various scales in terms of scope and time (Ostrom

14 The perfectly rational model of man adopted by neoclassical economists and some rational choice theorists can be considered to be a particular type of mental model in which individuals have a rather clear idea about the problem situation. 
and Janssen, 2002). Farmers sharing waters from a lateral canal develop an order of water distribution and appropriation. Such a local irrigation order is in turn sustained by the larger concerns of managing the main canal and coordinating the distribution of water among laterals. The management of the physical infrastructure is in turn conditioned by the way irrigation management relates to the broader issues of water resource management and economic development issues that are often managed in the context of national governance.

Several features of the multi-scale character of a hierarchic system are particularly important. First, structures and processes of different scales on different levels tend to have very different spatial and temporal attributes. For instance, irrigation at the tail end of a channel operates on a cycle very different from that at the head end, and even more different from the operation pattern of the larger channel. The operation of a SES involves institutional arrangements of multiple scales, each with different design imperatives. Second, structures and processes at different levels tend to affect one another. Usually the slower, larger levels constrain the behavior of the faster and lower levels (Gunderson and Pritchard, 2002). The operation of the channel that delivers water from a reservoir to laterals is likely to affect the operation of the systems that receive water from the laterals. Also the robustness of one level does not necessarily enhance the robustness of another level. For instance, subsystems that keep absorbing shocks at the local level tend to reduce the vigilance of the larger system. The synchronization of processes at different levels is of major importance.

\section{Coping with complexity in Taiwanese irrigation}

To attain a productive working order in irrigation requires that the dynamics embedded in the complex system be harnessed effectively (Axelrod and Cohen, 2000). The design of Taiwanese irrigation institutions has, to a large extent, allowed the irrigation systems to cope with such dynamics by dealing with the tasks of coordination, repertoire building, and nesting.

\subsection{Coordination}

A major feature of Taiwan's irrigation institutions is that they provide arenas and support for problem solving by farmers at the local level. Farmers are organized into self-organized Irrigation Groups (IGs), which are responsible for O\&M in the field. Farmers in an IG elect an IG leader, who is given the mandate to coordinate and liaise with IG members concerning O\&M activities. In some IGs, water guards are hired to help on water allocation and minor maintenance works.

The IGs are organized on the basis of hydraulic boundaries. In Taoyuan areas where a large number of ponds were in place for water storage, for example, the IGs are organized in accordance with the areas irrigated by individual ponds. By 
matching the boundaries of the IGs with hydraulic areas, the task of irrigation management is effectively compartmentalized into subtasks. That farmers at the local level are allowed to work out solutions to cope with 'localized' irrigation problems enables better utilization of local information. By the nature of its proximity to the local community, the IGs can draw upon social capital that has already been developed in the local community to attain coordination in O\&M (Lam, 1996a).

While the IGs enhance clustering among farmers within particular hydraulic areas, how IGs connect with one another affects the overall performance of the system as a whole. Closely knit communities are often fragile in dealing with external shocks or changes on a large-scale, and might not be consistent with one another in pursuing larger-scale collective actions (Buchanan, 2002; Watts, 2003). Research on 'small world phenomena' suggests that random links developed between individuals belonging to different communities can provide the glue that drastically shortens the social distance between the communities, hence reconciles clustering and connectedness. The random links do not have to be strong; the mere existence of these links serves a miraculous function of linking up closely knit communities.

In Taiwan, two institutional arrangements are in place to connect the clustered groups (the IGs). The first is the annual irrigation plans worked out by the IAs as the blueprints for water delivery. While the plans are so meticulous that even the amount of water allocated to a particular patch is specified, they are often not strictly followed in actual water distribution. These irrigation plans, however, serve a very important coordination function. The amounts of water to particular fields as specified in these plans are considered farmers' entitlements of water, which serve as the benchmark around which adjustments be made. These plans provide a mental map for farmers to engage in mutual adjustments.

Second, random links are put in place to bridge the IG leaders and the frontline staff of the IAs. The IAs' working stations in the field hold regular IG leaders meetings twice a year, usually scheduled for the time right before irrigation begins. Ad hoc meetings will also be held in case of emergencies. Whether these meetings can provide an effective arena for decision making and deliberation has been questioned. Anyone who has observed these meetings would agree that they are more like social gatherings and largely dominated by IA officials. Very often the attendance rate is low. Despite that, these meetings shorten the social distance between the IGs so as to enhance coordination and provide access to learning from one another (Watts, 1999, 2003). Other than the meetings, the IG leaders are also engaged in various social activities organized by the IAs. For example, every year an irrigation festival is organized at which some 'model IG leaders' will be given awards; also an IG leader is entitled to an 'overseas field trip' during his term of service to broaden his horizons. All these seemingly trivial and irrelevant activities help sustain the connectedness among the IG leaders and hence the IGs. 
Coordination in water delivery in Taiwan is maintained not by a grand plan or a pacemaker, but by an array of institutional arrangements that encourage local problem solving on the one hand, and local mutual adjustments on the other. The situation in Chianan provides a good case for illustration. In Chianan areas, irrigation water mainly comes from large reservoirs; rotation irrigation is practiced. The changing economic setting has triggered the development of a large array of rules to cope with the impact of macro-economic changes in disparate locations. While the farmers have not succeeded to adapt in every circumstance, some interesting systemic patterns can be observed. In general, farmers (and their IGs) in different locations along a canal would assess the profitability of farming (based upon their knowledge on the cropping patterns of their fields and the market situation) to work out different water allocation practices that require different levels of involvement and input on their part. Such flexibility of the institutions can cope with the low incentive mode of agriculture on the one hand, and retain a certain level of vibrancy in irrigation management on the other.

The viability of the flexible institutional arrangements in Taiwan depends on the IG leaders who are willing to coordinate farmers in local communities. A (de)stabilizing factor for the robustness of Taiwanese irrigation is whether the commitment and experiences of the IG leaders can be retained, strengthened, and reproduced. The IAs are aware of their importance, and have in recent years adopted measures to beef up the support and incentives for the IG leaders. In Taoyuan IA, for example, the IG leaders are allowed to operate aquaculture in the ponds that store irrigation water for the IGs. Profit from aquaculture provides additional incentives for the IG leaders to keep their posts. Other than material incentives, efforts have been made to strengthen the connectedness of IG leaders. In Taoyuan, the IG leaders are organized into associations. Also each managerial staff of the IA is required to visit the working stations at least twice a year. Although many IGs are not as active as in the past, the role of the IG leaders has become increasingly important for coordination.

A caveat is warranted, however, that the IAs' effort to adapt to the changing environment is not successful in every instance. Research has shown that IAs with different social-economic backgrounds tend to have different degrees of success in coping with change (Lam, 2001). Generally speaking, the IAs that have fewer endowments in terms of properties and financial resources tend to have a tougher time in the process of adjustment. The research has also found that farmers are in general less able and willing to adapt to change in systems where water is scarce and farmers have little control over the supply of irrigation water.

\subsection{Repertoire building and learning}

As discussed above, boundedly rational individuals make sense of the world by resorting to shared mental models that provide the assumptions and theories 
explaining the world. A robust SES should be able to generate and maintain a variety of mental models that could possibly be drawn upon for various problem situations.

Taiwanese irrigation systems are knowledge-rich. Knowledge generated in the process of irrigation management is systematically recorded and stored in handbooks and documents at different jurisdiction levels of the irrigation sector. These handbooks and documents, of course, do not necessarily provide the solution to every problem at hand; there have been instances in which farmers and irrigation managers were bewildered by exigencies that they had never encountered before. Yet the knowledge recorded in the handbooks does constitute a repertoire of ideas that provide the building blocks for working out mental models. The practice of water stoppage during droughts is a case in point. The basic idea, as recorded in the handbook, is that prolonging the irrigation cycle by a few days could reduce water use without doing harm to the crops. Yet exactly how long the water should be stopped, how water stoppage can fit in rotation irrigation, and how water stoppage should be managed would all depend on the physical as well as institutional setting of particular systems. During my fieldwork, I found a variety of water stoppage rules used in different IGs. There is also a high degree of cross-community learning.

Mental models concern not only the physical and operational dimensions of irrigation management, but also broader issues such as the orientation of the irrigation sector in the new political economic setting. The IAs are not merely engineering agencies, they are parastatal organizations owned by farmers, staffed by professional engineers and managers, controlled by local politicians, and supported and supervised by the government (Lam, 1996a). Such a combination of expertise enables the IAs to address irrigation management not only from an engineering perspective, but also from social and policy perspectives. Such capacity is particularly important in the context where not only individual IAs but also the whole irrigation sector is looking for a niche to re-orient itself. So when the IAs were asked to generate revenues, they could easily come up with such innovative ideas as partnering up with a power company to engage in hydraulic power generation.

Of course, the institutional design that includes individuals of different expertise and backgrounds does not always work to enhance irrigation management and the IAs. In fact, a (de)stabilizing factor affecting the robustness of Taiwanese irrigation is whether various interests involved in the IAs can be reconciled. When local politicians who control the IAs operated the organizations solely as a political mobilization machine, and farmers were unable to monitor and control these politicians effectively, one would expect a drastic loss of vibrancy of the institutions and the systems.

\subsection{Nesting}

To cope with the multi-scale nature of irrigation management, irrigation institutions serving activities of different scales at different levels are nested 
within one another. As mentioned, the IGs are organized around hydraulic (at the sub-lateral level) and community boundaries; above the IGs are working stations that are organized to cover a number of IGs, in accordance with larger hydraulic boundaries (at the lateral level). The IA headquarters oversee the overall irrigation management in particular regions. While each unit is given the task and much autonomy in managing irrigation in a particular area, it is at the same time supported and covered by a higher-level unit that manages a task of a larger scale (Moore, 1989; Lam, 1996a).

The nesting arrangements enhance complementarity and embeddedness (Lam, 1996a). Complementarity refers to the mutually beneficial division of labor among individuals in different capacities. Tasks of different scales call for different expertise and resources. For example, while the IGs might be able to help fix small leaks in canals, larger-scale maintenance works need to be dealt with by the working stations or even the headquarters.

Complementarity keeps the system flexibly decomposable. Units in a system could easily be re-grouped into units of different scales to cope with problems of different scopes. Managing water allocation in droughts is a good case in point. Depending on the scale and seriousness of the drought, rotation of different types involving working units of different scales could be adopted. When water shortage is mild and considered temporary, rotation in the form of farmers within an irrigation block taking turns to receive water would suffice. More serious water shortage might require that irrigation blocks take turns to receive water. When droughts happen, rotation might be practiced on the basis of areas irrigated by laterals. If the drought persists, rotation would be conducted on the basis of river systems.

Complementarity also serves as the safety valve that makes the system more robust to external shocks. The simplest form of safety valve is putting a certain degree of redundancy in place (Costanza et al., 2001). For example, instead of relying on the IG leaders to patrol the canals, the working staff will also do the patrolling. Another form of safety valve is substitution. For instance, one major strategy of the IAs to cope with the decreased incentive and input of farmers in irrigation management is to maintain the infrastructure as well as possible, so as to reduce the demand for farmer's input (Lam, 2005). Safety valves can also take the form of larger units providing buffers to smaller units. A most illustrative example of a buffer is the option of fallowing provided by the government. By absorbing farmers' risk, the fallowing option puts bounds on the demand for irrigation management, and avoids extreme situations.

Embeddedness refers to the intertwining of processes and rules that creates added value for the processes. For example, the IG leaders are responsible for water distribution at the field level. Yet there are situations in which water is very scarce or serious feuds between farmers exist; the moral authority wielded by the IG leaders alone might not suffice. Under these situations, the staff from the working stations or even the IA headquarters will back up the IG leaders to 
patrol the canals. The presence of the IA staff enhances the IG leaders' authority in discharging their duties.

Sometimes embeddedness takes the form of units at a higher level controlling excesses by units at a lower level. As mentioned, a major challenge facing Taiwan's irrigation institutions has been the changing nature of the IAs. As farmers face little incentive to get involved in irrigation management and are getting increasingly detached, the IAs are becoming farmers' organizations without farmers' involvement. The IA staff and the politicians who control the IAs become the de facto owners of the associations. Such a change threatens the viability of the IAs whose design is based upon the assumption of farmers' ownership (Lam, 2005).

To maintain the viability of the IAs, the government has adopted policy measures that set the boundaries for the operation of the IAs and hence minimized the extent of possible rent-seeking activities. These measures have been mainly focused on two areas. The first is the imposition of financial prudence. The IAs are not allowed to spend the money they earn from property sales on activities other than irrigation. Also the amount of subsidies to the IAs is tightly controlled. The second is to work out better laws and regulations for the operation of the IAs. Instead of relying solely on administrative control as before, ${ }^{15}$ the government has been trying to codify rules and laws that could provide a better legal framework for the operation of the IAs (AERC, 2003).

\section{Discussion}

In much of Asia in the last two decades, rapid economic development and urbanization have brought about significant changes to the macro politicaleconomic context in which irrigation is managed. The question of what can be done to help the irrigation systems to cope with the changes and to retain a certain level of vibrancy is of major academic and policy interest (Shivakoti et al., 2005). This study has looked into the experience of Taiwanese irrigation, which has shown a high degree of robustness to shocks and disturbances brought about by macro political-economic changes. Conceptualizing an irrigation system as a social-ecological system (SES), this study has examined the development and design of Taiwanese irrigation institutions, and how these institutions have enabled farmers and irrigation managers to cope with the dynamics in the SES, and hence contributed to the systems' robustness. Important features of the institutions are summarized in Table 1.

15 In the past, the interaction between the IAs and the central government was mainly through administrative orders by the government. A consequence was that, while the IAs tended to rely on the government for decisions; the government found itself not having sufficient resources to exercise effective control and this created administrative bottlenecks. 
Table 1. Institutional features that enhance system robustness

Imperatives for Coping with the Dynamics of Irrigation Systems as SES

1. Coordinating a Large Number of Autonomous Agents (Irrigator-Farmers)

2. Coping with the Limits of Human Cognition

3. Managing Multiplicity of Scales of Problems
Features of Taiwanese Irrigation Institutions

Strengthen the clustering of farmers by:

- matching the boundaries of problem-solving units, i.e. the Irrigation Groups (IGs), with hydraulic boundaries;

- allowing high degrees of autonomy to the IGs. Strengthen the connectedness among clusters by:

- working out irrigation plans to serve as the framework for interactions among the IGs;

- developing social networks among IGs leaders;

- putting in place ties between IG leaders and irrigation officials through regular yet infrequent rotation of irrigation staff.

To cope with macro political-economic changes, the clustering and connectedness have been enhanced by:

- allowing institutional adjustments by the IGs;

- strengthening the role of IG leaders and their networks.

Build a repertoire of mental models by:

- facilitating systematic information gathering at both the working stations and the IGs;

- codifying scenarios and relevant operational rules for irrigation management.

Facilitate learning by:

- allowing the IGs the flexibility of drawing upon and making adjustment to codified operational rules;

- encouraging cross-community learning in irrigation and farming matters.

Putting in place a diversity of ideas by:

- including individuals of different backgrounds and expertise in the Irrigation Associations (IAs).

To cope with macro political-economic changes, repertoire-building and learning have been strengthened by:

- further codifying and strengthening operational rules for irrigation management.

Put in place multi-level governance by:

- matching problems of different scales with organizational units at different levels of jurisdiction;

- defining clearly the degree of autonomy and responsibilities for organizational units at different levels.

To cope with the nesting of problems of different scales, complementarity between organizational units at different levels is attained by:

- keeping irrigation institutions flexibly decomposable;

- putting in place certain degrees of redundancy as well as substitutability of organizational units at different levels; 
Table 1. Continued

\begin{tabular}{ll}
\hline \hline $\begin{array}{l}\text { Imperatives for Coping with the Dynamics } \\
\text { of Irrigation Systems as SES }\end{array}$ & Features of Taiwanese Irrigation Institutions \\
\hline & having organizational units at higher jurisdiction \\
levels provide buffer for units at lower levels. & Embeddedness of organizational units at different levels is \\
also put in place by: & intertwining the processes and operation of \\
& organizational units at different levels; \\
$\bullet$ & having organizational units at higher levels control \\
possible excesses by units at lower levels. & To cope with macro political-economic changes, the \\
nesting of organizations has been strengthened by: \\
- specifying a clearer framework for the operation of \\
local irrigation institutions; \\
the government imposing a high degree of financial \\
prudence on the IAs; \\
- working out more detailed legal frameworks for the \\
interaction between the IAs and the government.
\end{tabular}

The major lesson from the Taiwanese experience is that a robust irrigation system is built upon institutions that allow effective coordination of the activities of a multitude of farmers, enhance the development and sustenance of a repertoire of ideas, and nest the problem-solving efforts of various scopes and scales in a complementary manner. These institutions enable individuals and organizations at different levels to engage in continuous learning and adaptation that, in turn, facilitates the systems' adaptation to the changing environment.

The lesson, however, goes beyond irrigation management. The issues addressed in this study - institutional design, the dynamics of institutional development, and complexity - are pertinent to the more general question of how individuals cope with complexity in a social-ecological system. A complex system is composed of a large number of mutually adapting human and biophysical elements whose rich patterns of interactions produce emergent properties that are not easy to predict (Ostrom, 2005). Many social systems and policy problem situations can be characterized as a complex system. Hence, an appreciation of the role and meaning of complexity, and a good understanding of how institutions can help cope with complexity are fundamental to policy analysis and action.

A note of caution, however, is warranted. While the Taiwanese experience offers good insights, it would be naïve to construe the Taiwanese irrigation institutions as the magic recipe for effective management of irrigation or SES, which could be easily transplanted to other settings. Institutions exist in particular historical junctures characterized by specific temporal and contextual features (Griffin, 1992; Hill, 1997). The discussion above has shown that the 
Taiwanese irrigation institutions are a product of not only rational institutional choices, but also the opportunities and constraints embedded in particular historical contexts and the temporal dynamics such as the lock-in effects.

The robustness of Taiwanese irrigation hinges upon a number of stabilizing and destabilizing factors. Perhaps the most important one is the existence of a certain level of commitment and the participation of farmers. While institutional design can help reduce the demand for farmers' commitment and self-organizing effort, it is no perfect substitute. When farmers totally retreat from the tripartite endeavor, and irrigation management becomes the battle of the sexes between the government and IA officials, the collapse of the system can be expected.

With the decline of agriculture and the increasing politicization of irrigation management, learning has become more confusing. Sometimes farmers could get stuck in a mental model that may provide short-term benefits for individuals but cause long-term damage to their systems. Perhaps the best example is the controversy concerning membership fees (Lam, 2005). When irrigation is portrayed as merely one type of public service that the government should provide for free, farmers and IA officials are getting more and more dependent; and tend to dwell on strategies that seek rent from the government.

Complementarity and embeddedness have enabled Taiwan's irrigation systems to adapt and adjust to the changing environment. Both complementarity and embeddedness, however, have their limits. When infrastructure is considered to be able to replace farmers' effort, and when IA staff are thought to be able to replace the IG leaders, the vibrancy of the system could easily be undermined (Lam, 1996b, 2001, 2005). What is more unfortunate is that individuals might not be even aware of the loss at first. When the deterioration reaches the threshold, cascading effect in terms of rapid deterioration could happen. Particularly, embeddedness would work only if the IAs remain vibrant and autonomous entities. When they are so embedded with the government that they lose their autonomy and self-organizing capacity, they could become de facto subordinate organizations of the government.

\section{References}

Agricultural Engineering Research Center (AERC) (1999), Review on the Functional Adjustment for the Irrigation Associations in Taiwan (I), Chungli: AERC. (In Chinese).

Agricultural Engineering Research Center (AERC) (2000), Review on the Functional Adjustment for the Irrigation Associations in Taiwan (II), Chungli: AERC. (In Chinese).

Agricultural Engineering Research Center (AERC) (2001), Review on the Functional Adjustment for the Irrigation Associations in Taiwan (III), Chungli: AERC. (In Chinese).

Agricultural Engineering Research Center (AERC) (2003), Drafts of Irrigation Rules and Regulations, Taipei: Council of Agriculture. (In Chinese).

Amsden, A. H. (1988), 'Taiwan's economic history: a case of Etatisme and a challenge to dependency theory', in R. H. Bates (ed.), Toward a Political Economy of Development, Berkeley, CA: University of California Press, pp. 142-175. 
Anderies, M. J., M. A. Janssen, and E. Ostrom (2004), 'A framework to analyze the robustness of social-ecological systems from an institutional perspective', Ecology and Society, 9(1): 18. [online] http://www.ecologyandsociety.org/vol9/iss1/art18/

Arthur, W. B. (1994), Increasing Returns and Path Dependence in the Economy, Ann Arbor: University of Michigan Press.

Axelrod, R. and M. D. Cohen (2000), Harnessing Complexity, NY: Basic Books.

Berkes, F. and C. Folke (1998), Linking Social and Ecological Systems: Management Practices and Social Mechanisms for Building Resilience, Cambridge: Cambridge University Press.

Buchanan, M. (2002), Small World, London: Phoenix.

Buthe, T. (2002), 'Taking temporality seriously: modeling history and the use of narratives as evidence', American Political Science Review, 96(3): 481-493.

Camazine, S., J. L. Deneubourg, N. R. Franks, J. Sney, G. Theraulaz, and E. Bonabeau (2001), Self-Organization in Biological Systems, Princeton, NJ: Princeton University Press.

Carlson, J. M. and J. Doyle (2002), 'Complexity and robustness', Proceedings of the National Academy of Science, 99(1): 2538-2545.

Chen, C. M. (1996), 'A study of the implications of the restructuring of the irrigation associations for property management', Irrigation Magazine, 42(1): 26-41.

Chen, C. M. (1997), 'The evolution of irrigation organization in Taiwan', Irrigation Magazine, 43(11): 6-26. (In Chinese).

Chen, C. M. (1999), Problems affecting the Sustainability of Irrigation Associations: Land Use, Government Subsidies, and the Establishment of Funds, Tainan: Chianan Irrigation Association. (In Chinese).

Chen, S. C. (1997), 'Irrigation associations under the sun: a statistical analysis of the operation of the associations', Irrigation Magazine, 43(4): 36-47. (In Chinese).

Chinese Agricultural Engineering Association (CAEA) (1995), A Study of the Advantages and Disadvantages of Turning the Irrigation Associations into Government Agencies, Taichung: Taiwan Joint Irrigation Association. (In Chinese).

Costanza, R., B. S. Low, E. Ostrom, and J. Wilson (2001), Institutions, Ecosystems, and Sustainability, Boca Raton: Lewis Publishers.

Council of Agriculture (COA) (2003), Agricultural Statistics Yearbook 2002, Taipei: Council of Agriculture.

Council for Economic Planning and Development (CEPD) (1996), Taiwan Statistical Data Book, Taipei: Council for Economic Planning and Development.

Denzau, A. and D. C. North (1994), 'Shared mental models: ideologies and institutions', Kyklos, 47: 3-31.

Directorate-General of Budget, Accounting and Statistics (2002), Statistical Yearbook of the Republic of China 2002, Taipei: Executive Yuen.

Directorate-General of Budget, Accounting and Statistics (2003), Statistical Abstract of National Income in Taiwan Area, The Republic of China 1951-2003, Taipei: Executive Yuen.

Foster, K. W. (2001), 'Associations in the embrace of an authoritarian state: state dominance of society?', Studies in Comparative International Development, 35(4): 84-109.

Griffin, L. J. (1992), 'Temporality, events, and explanation in historical sociology', Sociological Methods and Research, 20(4): 403-427.

Gunderson, L. H. and L. Pritchard, Jr. (2002), Resilience and the Behavior of Large-Scale Systems, Washington: Island Press.

Hill, G. (1997), 'History, necessity, and rational choice theory', Rationality and Society, 9(2): 189-213. 
Jen, E. (2002), 'Stable or robust? What's the difference?', Working Paper, Santa Fe Institute.

Jones, B. D. (2003), 'Bounded rationality and political science: lessons from public administration and public policy', Journal of Public Administration Research and Theory, 13(4): 395-412.

Ka, C. M. (1995), Japanese Colonialism in Taiwan: Land Tenure, Development, and Dependency, 1895-1945, Taipei: Westview Press.

Lam, W. F. (1996a), 'Institutional design of public agencies and coproduction: a study of irrigation associations in Taiwan', World Development, 24(6): 1039-1054.

Lam, W. F. (1996b), 'Improving the performance of small-scale irrigation systems: the effects of technological investments and governance structure on irrigation performance in Nepal', World Development, 24(8): 1301-1315.

Lam, W. F. (1998), Governing Irrigation Systems in Nepal: Institutions, Infrastructure, and Collective Action, Oakland: CA: Institute for Contemporary Studies (ICS) Press.

Lam, W. F. (2001), 'Coping with change: a study of local irrigation institutions in Taiwan', World Development, 29(9): 1569-1592.

Lam, W. F. (2005), 'Reforming Taiwan's irrigation associations: getting the nesting of institutions right', in G. Shivakoti, D. Vermillion, W. F. Lam, E. Ostrom, U. Pradhan, and R. Yoder (eds), Asian Irrigation Systems in Transition: Responding to the Challenges Ahead, New Delhi/Thousand Oaks/London: Sage Publications.

Lam, W. F. (2006), 'Designing institutions for irrigation management: comparing irrigation agencies in Nepal and Taiwan', Property Management (Forthcoming).

Lansing, J. S. (1991), Priests and Programmers: Technologies of Power in the Engineered Landscape of Bali, Princeton, NJ: Princeton University Press.

Liao, C. H., C. C. Huang, and H. H. M. Hsiao (1986), The Development of Agricultural Policies in Post-War Taiwan, Taipei: Academia Sinica.

Moore, M. (1989), 'The fruits and fallacies of neoliberalism: the case of irrigation policy', World Development, 17(11): 1733-1750.sxs

Moore, M. (1993), 'Economic structure and the politics of sectoral bias: East Asian and other cases', Journal of Development Studies, 29(4): 79-128.

North, D. C. (1990), Institutions, Institutional Change and Economic Performance, Cambridge: Cambridge University Press.

Ostrom, E. (2005), Understanding Institutional Diversity, NJ: Princeton University Press.

Ostrom, E. and R. Gardner (1993), 'Coping with asymmetries in the commons: self-governing irrigation systems can work', Journal of Economic Perspectives, 7(4): 93-112.

Ostrom, E. and M. A. Janssen (2002), 'Beliefs, multi-level governance, and development', Working Paper, Workshop in Political Theory and Policy Analysis.

Pierson, P. (2004), Politics in Time, Princeton, NJ: Princeton University Press.

Pingali, P. L., M. Hossain, and R. V. Gerpacio (1997), Asian Rice Bowls: The Returning Crisis?, NY: CAB International in association with the International Rice Research Institute.

Shivakoti G., D. Vermillion, W. F. Lam, E. Ostrom, U. Pradhan, and R. Yoder (eds) (2005), Asian Irrigation Systems in Transition: Responding to the Challenges Ahead, New Dehli: Sage.

Simon, H. A. (1962), 'The architecture of complexity', Proceedings of the American Philosophical Society, 106(6): 467-482.

Simon, H. A. (1985), 'Human nature in politics: the dialogue of psychology with political science', American Political Science Review, 79: 293-304. 
Stavis, B. (1974), Rural Local Governance and Agricultural Development in Taiwan, Ithaca, NY: Rural Development Committee.

Sylvan, D. and S. Majeski (1998), 'A methodology for the study of historical counterfactuals', International Studies Quarterly, 42: 79-108.

Tetlock, P. E. and A. Belkin (1996), Counterfactual Thought Experiments in World Politics: Logical, Methodological, and Psychological Perspectives, Princeton, NJ: Princeton University Press.

Thelen, K. (2004), How Institutions Evolve, Cambridge: Cambridge University Press.

Watts, D. J. (1999), Small World: The Dynamics of Networks between Order and Randomness, Princeton, NJ: Princeton University Press.

Watts, D. J. (2003), Six Degrees, New York: Norton \& Co.

Williams, J. F. (1994), 'Vulnerability and change in Taiwan's agriculture', in M. A. Rubinstein (ed.), The Other Taiwan: 1945 to the Present, NY: M.E. Sharpe, pp. 215-233.

Wu Huang, S. (1993), 'Structural change in Taiwan's agricultural economy', Economic Development and Cultural Change, 42(1): 43-65. 